\title{
Print Media Framing of Women in Entrepreneurship: Prospects for Women Empowerment
}

\author{
${ }^{1}$ Samuel Okere, Ph.D \& ${ }^{2}$ Justina Sam-Okere, Ph.D \\ ${ }^{1 .}$ Babcock University, Department of Mass Communication \\ 2. Babcock University, Department of Political Science \& Public Administration
}

\begin{abstract}
That women constitute a vital force in the building of any nation is no longer a matter of debate. It is also an established fact that the society operates on structures which impede women's growth. To re-address this imbalance, various nations of the world including Nigeria are utilising every potent organ to empower women in order to maximize their potentials. One of such organs is the media. Being a powerful agency for agenda setting, the media can and indeed do influence the conscience of the society to interpret reality from its chosen angle of presentation of events and personalities. This paper which is exploratory in nature adopted the content analysis method. This it did by exploring the media framing of women participants in 'Big Naira Begins with Small Kobo", a feature column on entrepreneurship in The Punch, a leading national newspaper in Nigeria. The column was chosen for the study because it is the signature page of the business desk of that newspaper. From the analysis, the paper concludes that print media framing of women in the world of entrepreneurship can serve as an important tool for enhancing their socio-economic empowerment. Therefore, for The Punch newspaper to fulfil the mission of being a veritable instrument of social change, it will have to increase its numerical quota frame of women while maintaining the characterisation frame of positive image in its column feature of "Big Naira Begins with Small Kobo".
\end{abstract}

Key Words: Media Framing; Women in Entrepreneurship; Women Empowerment

Paper Type: Research paper

\section{Introduction}

Women empowerment is a social need that should be addressed by virtually every instrument of capacity development. This is so because the growth and development of any nation is tied to the fundamental role of women as wives, mothers, and indeed the first teacher in the home. To this end therefore, women are highly indispensable. Equipping them for maximum performance yields unquantifiable result for social equilibrium. In recognition of the important role of women in society and the need to properly position them, the United Nations in September 2000 entrenched the promotion of gender equality and women empowerment as one of the eight cardinal points in a strategic development global document known as Millennium Development Goals (MDGs).

Nigeria was among the 192 United Nations member-states and at least 23 international organisations that endorsed this document. By endorsing the Millennium Development Goals, they are making an eloquent statement that by 2015 they would have used all means available to them to improve human wellbeing. The eight cardinal points that make up the MDGs are:

1. Eradicate extreme hunger and poverty

2. Achieve Universal Primary Education

3. Promote gender equality and empower women

4. Reduce child mortality

5. Improve maternal health

6. Combat HIV/AIDS, malaria and other diseases

7. Ensure environment sustainability

8. Develop a global partnership for development

The media, whether electronic or print, constitute one veritable means of effecting social change (Dominick, 2011; Orewere, 2006,). In fact, the power of the media in this regard is fundamental in the study of the interrelationship between the media and the society. From ancient times through various civilisations, the capacity of the media as a catalyst for social change is highly acknowledged.

In view of the immense benefits that can be derived from utilising the media for such a result, this paper is critically examining the prospects of locating print media framing of women participation in entrepreneurship at the intersection of Nigeria's march towards the attainment of the third item in the 
Millennium Development Goals - promotion of gender equality and women empowerment. This is an exploratory study; it is an extraction from an ongoing research on the need to use the print media to enhance the realisation of gender equality especially as it relates to empowering women in such a way that they would have fulfillment being an integral part of the society.

Three concepts, media framing, women empowerment and women in entrepreneurship form the central thought of this paper. By media framing we refer to the act of selecting and presenting reality by the media which informs the way the audience will regard and interpret such reality. By women Empowerment we refer to the ability of women to exert control over aspects of their own lives in such a way that they can participate effectively in group efforts for social change. Women in entrepreneurship as one of the key concepts in this paper refers to the participation of women in such commercial activities that may often involve personal financial risks.

The newspaper is one print medium that has been applied to use in Nigeria as an instrument of social change. It has reasonable patronage; the society considers of importance, issues featured therein. Newspaper shares with the rest media of mass communication in a current wave of radical transformation. Alao and Asekun-Olarinmoye (2007: p.2), opine that in this regard, the media of mass communication are moving out of "the traditional role of educating, informing and entertaining to more scientific roles." They outline three of such roles:

1. Stimulating debates and sensitising people for participatory decision-making and action.

2. Helping people acquire new knowledge and needed skills

3. Using communication to promote hard work, cooperation and coordination between various organizations through multi-disciplinary programmes.

It is in recognition of the immense contribution of newspaper to nation-building that it is chosen as the print medium of study in this paper. The Punch, a leading national newspaper in Nigeria has a popular feature column on entrepreneurship entitled "Big Naira Begins with Small Kobo." This feature column which appears on page four is the signature page of the business desk of the newspaper. For most days of the week, the newspaper presents both fictional and nonfictional characters in an entrepreneurial encounter.

By applying the literary technique of characterisation as a means of content analysis, this paper explores the framing of the female personae in the features. This is done as a means of seeking answers to two basic questions:

1. Does The Punch feature column, "Big Naira Begins with Small Kobo" consider gender balance in its personae selection and framing?

2. Can this framing mode be utilised as a tool for realising the Millennium Development Goal of gender equality and women empowerment?

The essence of these questions is to devise a means of probing into how The Punch, a leading national newspaper in Nigeria can function as an additional instrument through which Nigeria can realise her resolve to actualise gender equality and women empowerment, a strategic item in the Millennium Development Goals.

To maintain currency of discourse and in line with the exploratory design, this paper has chosen for its study population, the 181 editions of the newspaper for the first half of the year 2011 (that is, 31 editions each for the months of January, March, and May; 28 editions for the month of February, and 30 editions each for the months of April and June). Wednesday edition is also chosen because it is the most consistent. Whereas the feature may be absent in some other days, it never fails to appear every Wednesday.

Through a random sampling technique, a sample size of three months (February, April and June) was derived. This arrangement gives a total of 13 editions for discussion out of the 26 editions of the three months. With the 13 editions, the discussion adopts the pattern of characterisation, a literary technique that gives the reader/audience the opportunity of understanding the dramatis personae in a work of art.

\section{Theoretical Framework}

Two theories that are germane to this study are are agenda setting theory and cultural modernity theory. With regard to agenda setting theory, media scholars explain the pervasive influence of the mass media on the audience with the agenda -setting theory posited by Maxwell McCombs in 1972 and further strengthened the following year by Donald L. Shaw. They are of the view that although the mass media may not tell us what not to think, they eventually tell us what to think about. As Anaeto, Onabajo and Osifeso (2008: p.89) put it, "Although we have a right to think what we want to think, but surprisingly, we tend to think most of those things the media highlights as important". Simply put, the theory says the way mass media audience attach importance to the issues they access from the media is dependent on the level of importance that the media attach to those issues. 
Emmet (1966) had laid the foundation for this theory when he observed that the pressure the mass media exert on the audience is such that has the capacity of modifying the behavior of the audience to the extent that their attitudes, perception and ambition could be altered. Severin and Tankard (1992) have lent voice to this theory by emphasizing the fact that the audience of the mass media pattern their thought process after the information that the mass media supply to them. In subscribing to this theory, Weaver (1984) argues that although the relationship between media message and its influence on the audience may not be a causal one, there is no doubt that there is an intricate link between media ranking of issues and the priority the audience give to such issues. In interpreting how the media set agenda for the audience, Oladeinde and Ajibola (2009:p.4) argue that the media through event selection and presentation manipulate audience perception to the subjective view of the media. Thus the audience tends unwittingly to perceive reality from a mediated view. These scholars assert that 'What we know about the world is largely based on what the media decide to tell us. Specifically, the result of this mediated view of the world is that the priorities of the media strongly influence the priorities of the public. Elements prominent on the media agenda become prominent in the public mind'.

The second theory on which this paper is built is cultural modernity theory. This theory was first advanced by R. Inglehart, P. Norris and C. Welzel in their 1992 study of gender equality and democracy .The major tenet of this theory is that when economic development is converted into a cultural process of human development the result will be an emancipated worldview. This in turn will give rise to self expression values that are fundamental to human choice and autonomy. In this general atmosphere of rising emancipative values, society paves the way for individuals to have equal opportunities to control their circumstances and contribute meaningfully to social change. Gender no longer determines human limitations; it is rather ability that matters. The overall effect is that women will have increased opportunities for self actualisation in all spheres of life (Inglehart and Welzel, 2005).

The two theories reviewed above are considered relevant to this paper because they help to explain how the framing of women in entrepreneurial participation can influence their aspiration. The roles assigned to the female characters in the feature columns have the tendency of affecting women to model those female characters. In addition, such a framing is only meaningful in a society like Nigeria that is beginning to make conscious efforts to encourage women's participation in virtually every aspect of nation building.

\section{Nexus between Media Framing and the Empowerment of Nigerian Women}

All the media of mass communication have designed means of choosing from among the many events and issues that take place in the society and presenting them to the audience. In doing this, they place emphasis in some and de-emphasise others. Whatever they emphasise, either through the choice of diction or frequency of presentation has a way of dictating to the audience on how to make interpretations ((D'Angelo, P \& Kuypers, J., 2010). This act is what media scholars have termed media framing.

Framing plays a dominant role in shaping how media audience will receive and interpret reality. According to Watson and Hill (2006:p.105), "Framing constitutes a narrative device. What is not on the page of a newspaper is 'out of frame'; what does not appear within the frame of the TV is off the public agenda". Media framing may appear to the unsuspecting audience as an unreflective act; but the reality is that it is a conscious effort. Its purpose is to dictate for the audience how to interpret media messages. This fact is adumbrated by Oladeinde and Ajibola (2009: p.44):

Frames are often presented in media analysis as something adopted relatively unreflectively by journalists or audience as social constructions but as primary attributes of events that reporters are merely reflecting...Although it might appear as if the media use frames 'unreflectively', but by selecting certain facts from a continuous flow of information, emphasizing specific issues, or events in specific order, journalists have the ability to influence attitudes, beliefs and behaviours in a number of ways.

The Nigerian media, like all media in other parts of the world take their framing cue from the social milieu of their existence. The media professionals - reporters, writers and editors are products of the society. They understand how their audience think and so in their framing act, they deliberately reflect what the audience will unsuspectingly accept. This is often drawn from socio-cultural structures inherent in the society.

The Nigerian society has socio-cultural structures that have defined status and capacity development expectations for the two genders. These structures are designed in such a way that women are placed at a less vantage position (Amali, 2000). The implication is that the full participation of women and indeed their craving for fulfillment are not often met (Orjinta, 2007). Both distant and current history attest to the fact that Nigerian women have the capacity to be change agents in the society based on their heroic exploits ( Adeleke, 2002; Obafemi, 2006; Ogidefa 2008; Umehia, 2010; Dibie, 2010). In spite of the well tested understanding that there 
is nothing intrinsically wrong with women in terms of their capacity to contribute to nation-building, stereotypes abound in their social construction.

Thus, Nigerian women often find themselves playing the second fiddles. They are often at the receiving end despite the fact that when placed on an equal pedestal with the men folk, performance can only by measured by individual ability and not on natural physiological difference. To maintain the status quo in favour of the men folk, several spurious myths and legends of the weak nature of women are created and sustained. The resultant effect on the women is a docile acquiescence. The remarks of Kofi Annan, former Secretary General of the United Nations General Assembly is particularly relevant to the Nigerian situation:

When women are fully involved, the benefits can be seen immediately; their children are better educated; they are healthier and are better fed; they are better able to protect themselves against AIDS and other diseases, their families' income and economy improve. And what is true of families is true of communities...ultimately, indeed... of whole countries (Kofi Annan in an Address to UN General Assembly in 2002).

The idea of empowerment as maintained in this paper is that of involvement and participation. While some radical feminist scholars may advocate a total rejection of the natural complementary male-female relationship, the position maintained in this paper is that the recognition of the worth of women in the Nigerian society and the attendant creation of an enabling environment for their participation in nation-building is a fundamental step for their empowerment. Thus, this paper shares the view of Zummerman, (1990a: 75 cited in Stein, 1997: 63) that there is a bidirectional relationship between empowerment and participation. As he puts it "empowered persons are more likely to participate in an organization or the society at large, while on the other hand, participation promotes empowerment."

Encouraging women therefore, to participate in key societal activities whether economic or political is a deliberate effort to engender empowerment. This view aligns with the definition of empowerment by Wallerstein and Bernstein (1988:380 cited in Stein 1997):

Empowerment is a social action process that promotes participation of people, organizations, and communities in gaining control over their lives in their community and large society...Empowerment is not characterized as achieving power to dominate others, but rather power to act with others to effect change

Women empowerment features prominently in the National Economic Empowerment and Development Strategies (NEEDS), one of the fora through which Nigeria hopes to achieve the Millennium Development Goals. In chapter Four of the working document of NEEDS entitled "The Social Charter: Investing in the People", the federal government of Nigeria states in unequivocal terms that "NEEDS seeks to fully integrate women by enhancing their capacity to participate in the economic, social, political and cultural life of the country" (p.440). The document outlines the measures that will be adopted to do this.

They are:

1. Ensure equitable representation of women all over the country in all aspects of national life by using affirmative action to ensure that women represent at least 30 percent of the workforce, where feasible.

2. Implement the provisions of the UN Convention on Elimination of all forms of Discrimination against women.

3. Support legislation for the abolition of all forms of harmful traditional practices against women.

4. Mainstream women's concerns and perspectives in all policies and programmes.

5. Promote access to microfinance and other poverty alleviation strategies, with a view to reducing poverty among women.

6. Reduce women's vulnerability to HIV/AIDS and other sexually transmitted diseases by empowering them through sustained advocacy, education, and mobilization.

7. Establish scholarship schemes at the secondary and tertiary levels to expand educational opportunities for female students where necessary. Expand adult and vocational educational programmes that cater to women beyond formal school age.

8. Increase the access of women, youth, and children to information on key national issues

9. Provide social security for unemployed women, youth, and poor children 


\section{Analysis and Discussion}

The thrust of this paper is an exploration of how The Punch has framed women characters in the entrepreneurial feature article "Big Naira Begins with small kobo." The phrasing of the title of this feature column reinforces the meaning of the time-tested expression, "Tiny drops of water make a mighty ocean". By extension, this column which teaches the fundamentals of entrepreneurship makes a bold statement on the capacity of the dramatis personae to hold sway in economic activities. These dramatis personae function therefore as stock characters depicting the capacity of the gender that they represent. It is in this light that the import of media framing can be appreciated.

Table 1: Frequency Distribution of the Feature Column per Month

\begin{tabular}{|l|l|}
\hline Month & Number of Times \\
\hline February & 4 \\
\hline April & 4 \\
\hline June & 5 \\
\hline
\end{tabular}

Table One shows that for the three months under discussion, "Big Naira Begins with Small Kobo" is featured 13 times (that is, four times each for the months of February and April and five times for the month of June. In line with the discussion, it is necessary to determine the gender balance in these 13 editions. This information is supplied in Table Two.

Table 2: Gender Distribution of Dramatis Personae per Month

\begin{tabular}{|l|l|l|}
\hline Month & Male & Female \\
\hline February & 2 & 2 \\
\hline April & 2 & 2 \\
\hline June & 5 & 0 \\
\hline Total & 9 & 4 \\
\hline
\end{tabular}

Table Two provides the answer to the first Research Question in this study: Does The Punch feature column, "Big Naira Begins with Small Kobo" consider gender balance in its personae selection and framing?

Based on the available data, it is seen that out of the 13 editions under study, "Big Naira Begins with Small Kobo" features male dramatis personae nine times and females four times. This shows that there is an attempt to project both male and female personae in this feature column. However, the frequency of female personae that participated in the studied sample shows a negligible effort in projecting women. The gap between nine and four is so wide. This framing seems to reflect societal stereotype where women are made to play second fiddles. The frequency of this framing can heighten the fears of those who accuse the society of marginalising women.

It is a known fact that the media often choose to present reality from a subjective view and beam such view on the audience. Over time, the audience will begin to interpret reality the way they see it being projected by the media. In light of this, the obvious surmising is that there is a noticeable imbalance the way the studied sample has featured women vis-à-vis their male counterparts. If the media were just a docile apparatus it would not cause so much concern. But because the effect of media framing is pervasive, radical and veritable as an instrument of social change, the situation therefore calls for a reassessment.

In reality, are women inactive in economic activities especially at the entrepreneurial level? A cursory observation of the Nigerian situation proves otherwise (Olawoyin, 2009). Nigerian women are very active participants in entrepreneurship, the kind that "Big Naira Begins with Small Kobo" discusses. Drawing inference from the data in this table under discussion it would be necessary to urge The Punch newspaper to make a conscious effort in its framing as a tool for helping the nation realize gender equality and women empowerment advocacy. It is the prerogative of the editor to make final decisions on what constitutes the content of every newspaper edition. There is every need therefore for the editor to put up some critical reasoning with a view for gender balance while making up the editorial content of the page. Otherwise, what seems a mere omission could be misconstrued for deliberate act of gender inequality. The drop in female participation from equal participation with men in the months of February and April to zero participation in the month of June leaves much to be desired.

The last segment of the discussion and analysis is an attempt to answer Research Question Two: Can this framing mode be utilised as a tool for realising the Millennium Development Goal of gender equality and women empowerment? 
To address this question, the exercise will adopt the style of textual analysis by paying attention to the characterisation of the female entrepreneurs in the feature

The texts for analysis are the four editions in which female characters are featured. These are two times each in the months of February and April.

On February 2, the entry is captioned "Dealing in hair extension accessories as extra source of income". In this feature, a female character named Miss Rachael Edike is presented as the entrepreneur of the day. Paragraph four of the feature, the point at which Miss Edike is introduced reads:

According to a foremost beauty promoting outfit, Levels Beauty Shop, Abuja, Miss Rachael Edike, dealing in hair extension is one business that is profitable, if only the individual involved knows the tricks and also has enough money to invest in the trade.

The next paragraph reads thus:

She says, It is a business with very high turnover and you have different products of different qualities as well. Because of the segmentation, there are products that can satisfy all categories of users. One thing is that if you invest in it, you will never be idle even though its boom is seasonal"

In this feature, the story of Miss Edike is one of success. She is a trail blazer in this business. She operates in the high brow city of Abuja and this she does with remarkable progress.

Each of the features has a check list captioned "Essential Points". These are:

1. Good knowledge of the product is essential

2. One can start the trade with $\mathrm{N} 40,000$

3. Location and product quality are crucial to business growth

4. Sincerity in dealings with customers is key to business expansion

When weighed against these "Essential Points" there is no doubt that Miss Edike is framed positively. She knows what it takes to be in this business and she is applying the strategies maximally.

The second and last feature for the month that has a female persona is on February 9, entitled "Finding Entrepreneurial lifeline in new building technology". The persona, Mrs. Monsurat Omotayo is introduced in paragraph 5:

According to a Florida, united States-based construction products manufacturing firm, CTI International's Managing Director, Mrs. Monsurat Omotayo, the new innovation is a range of products that are loaded with windows of opportunity for business-minded people in Nigeria, especially those who would want to distribute and apply the products for customers' services"

This is another success story. Mrs. Omotayo is an accomplished entrepreneur. She is a role model, an accomplished business woman. The essential points which she measures up to are:

1. Wide product shape

2. Active and large market

3. Low initial capital

4. Can be combined with other trade.

Female participation in the month of April begins on the $6^{\text {th }}$ of the month. In this feature, Mrs. Ayodele LadipoAjayi is introduced in paragraphs six and seven. The feature is captioned "Running a standard beauty salon". The story of Mrs. Ayodele goes thus:

The Chief Executive Officer, Stylistic Unisex, Mrs Ayodele Ladipo-Ajayi, is one of the entrepreneurs making professional beauty services available in the country. At Stylistic Unisex, she specializes in providing her customers with different types of hairstyles - manicure and pedicure, makeup, different beauty treatments and trainings among others

This is also a success story. The checklist of her success is:

1. Training is important

2. Get the right equipment

3. Customers need conducive environment

4. Good customer relations essential

The last feature is the story of Ms Omowunmi King entitled "Growing your business with facebook, twitter. The essential points based on which she is scored are: 
1. Know the differences in social media usage

2. Have separate accounts for personal and business purposes

3. Identify the target audience

4. Know the favourite social networks used by the target audience

5. A social media policy must be in place for your business

In relation to her performance sheet, the first paragraph gives her this introduction:

Ms Omowunmi King is a businesswoman who deals in women clothing, bags and shoes. She relates her experience on how lack of a clear differentiation between her personal account and a business account on her social network media almost ran her business aground. King says being a heavy user of the social networks, she felt that the traffic on the sites will help boost her business, so she spent a lot of energy and time trying to get sales through the social media, but to her surprise she could not achieve much.

Why did she fail? She says it did not work as projected because she did not make a distinction between having an account for social networking and a business account.Ms King is a typical female stereotype. She is naïve, wasteful and only wise after she has lost so much. Hers is a negative image. She neither motivates nor serves as a role model.

The summation of the characterisation discussed so far provides the answer to Research Question Two: Can this framing mode be utilised as a tool for realising the Millennium Development Goal of gender equality and women empowerment?

Three out of the four portraits present the female persona as successful entrepreneurs. Such a framing has the tendency of providing hope and fulfillment for women. The women who participated in these features are women of great potential and feat for success in entrepreneurship. They can become role models for other women who may aspire to enter into the world of entrepreneurship. In line with the principles of agenda setting and media framing, these features have the capacity of playing complementary role in the march towards the attainment of the third item in the Millennium Development Goals which is to promote gender equality and empower women.

\section{Recommendations}

In view of the impact of media framing, this paper makes the following recommendations on the feature column "Big Naira Begins with Small kobo"

1. The tempo of the column should be sustained.

2. There should be a deliberate effort to improve on the frequency of entry for female dramatis persona to ensure gender balance.

3. The newspaper needs to review its search for women entrepreneurs to reflect the social reality in Nigeria. Three of the four women analysed are in conventional "women business." Only one is in a "male dominated area". This selection has the tendency of conditioning the audience to believe that women succeed more in women business basically. There is the need therefore to feature female entrepreneurs more in the so called male dominated businesses.

\section{Conclusion}

Media messages have the capacity to influence and indeed shape the society. The frame given to the women under study determines how the audience will interpret and ascribe values to them. To the extent that three out of the four women featured are successful entrepreneurs, one can say that The Punch is acting as a complementary agency of women empowerment. However, in comparing the frequency with which men and women are featured, the reverse becomes the case. Of the three editions studied, men are given nine slots while women occupy only a beggarly four slots. For The Punch to fulfil the mission of being a veritable instrument of social change, it will have to increase its numerical quota frame of women while maintaining the characterisation frame of positive image in its column feature of "Big Naira Begins with Small Kobo".

\section{References}

[1] Dominick, J (2011). The dynamics of mass communication: Media in the digital age (1 $1^{\text {th }}$ edition). New York: McGraw-Hill

[2] Orewere, B. ( 2006), The communicator and the audience. Jos: Karis Publications

[3] Alao, D. and Asekun-Olarinmoye, S. (2007). "The Media and Peace Process: A Review of the Role of the Media in Conflict Resolution - The Obasanjo/Atiku Crisis" Contemporary Humanities, Volume 1, pp.1-11.

[4] Anaeto, S.; Onabajo O. and Osifeso J. (2008). Models and Theories of Communication. Lagos: African Renaissance Books Inc.

[5] Emmet B. (1966). Journal of Royal Statistical Society Vol. 12 Part 1 
[6] Severin W.and Tankard J. (1972) Communication Theories: Origins, Methods and Uses Longman Publishing Company

[7] Weaver, D. (1984) Media Agenda-Setting and Public Opinion: Is there a Link? In R. Communication Yearbook 8, (pp 680-691). Beverly Hills: SAGE Publications

[8] Oladeinde, R. and Ajibola, O. (2009). "The Dialectics of Media Framing of the Niger Communication, Vol. 2, No. 1 pp.39-58

[9] Inglehart, R., Norris P., and Welzel, C. (2005). Modernization, Cultural Change and Sequence. Cambridge University Press

[10] D’Angelo, P. \& Kuypers, J. (eds.) (2010). Doing news framing analysis: Empirical and theoretical perspectives. New York: Routledge

[11] Watson, J and Hill, A. (2006). Dictionary of Media and Communication Studies ( $7^{\text {th }}$ edition) London: Hodder Arnold

[12] Amali, E. (2000). "Gendered Economics and Women's Inclusion in Economic Politics in a Democratic Era: A Nigerian Perspective" in Oyin Ogunba (ed.) The Empowerment of the Civil Society in a Democracy:Nigeria and the United States of America. Ile-Ife: American Studies Association

[13] Orjinta, A. (2007). "Women's Oppression, Suppression and Repression in African of Mass Communication, Vol.1 No. 3 pp.157-165

[14] Adeleke, V. (2002). "Nigerian Women and national Development". Babcock Journal of 1 no. 1 pp.73-89

[15] Obafemi, O. (2006). "Gendered Politics and Theory of Democratic Culture: The Nigerian Female Writers' Response”. In Salihu, H., Amali, E., Fayeye, J., Oriola, E. (eds.) Democracy and Development in Nigeria. Vol. 3 Lagos: Concept Publications

[16] Ogidefa, I. (2008). "Women and Politics in Nigeria." Retrieved on January 15, 2013 from http. //beyondJane.com/women and politics in Nigeria.

[17] Umeha, C. (2010). "Women: The Journey to Political Relevance." Sunday Champion from http.// www.champion.comng/index pup category

[18] Dibie, R. (2009). "Globalization and Women Empowerment in Africa" in Globalization and Third World Women, Ligaya LindioMcGovern and Isidor Wallimann, (edited). Adershort, England: Ashgate

[19] Stein, J. (1997). Empowerment and Women's Health: Theory, Methods and Practice.

[20] National Economic Empowerment and Development Strategies (NEEDS). (2005). Abuja:National Planning Commision, Nigeria

[21] Olawoyin, O. (2009). "African women in informal economy in the twentieth century" in Ikpe, E. (ed.). Women and power in Africa in the twentieth century. Pp.138-150. Lagos: Fragrance Communications Publishers
Traditional Culture.” Babcock Journal

online. Retrieved on February 19, 2013 